\title{
Aplicação de técnicas multivariadas no estudo da divergência genética em cana-de-açúcar ${ }^{1}$
}

\author{
Application of multivariate techniques in the study of genetic diversity in sugarcane
}

\author{
João de Andrade Dutra Filho ${ }^{2 *}$, Luiz José Oliveira Tavares de Melo², Luciane Vilela Resende ${ }^{3}$, Clodoaldo José \\ da Anunciação Filho e Gerson Quirino Bastos ${ }^{4}$
}

\begin{abstract}
Resumo - Estudos sobre divergência genética são importantes na identificação de genitores potenciais para a obtenção de novos indivíduos com maior efeito heterótico. Em cana-de-açúcar esses estudos assumem fundamental importância, pois com o passar do tempo as variedades comerciais devem ser substituídas de suas áreas de cultivo, devido a sérios declínios agronômicos e industriais ocasionados pela degenerescência varietal. Sendo assim, o objetivo deste trabalho foi avaliar a divergência genética em progênies de cana-de-açúcar, através de técnicas multivariadas, com base em oito caracteres agroindustriais. O trabalho foi conduzido na área agrícola da Usina Santa Tereza, município de Goiana (PE), durante o ano agrícola 2007/2008. Foi utilizado o delineamento experimental casualizado em blocos completos com cinco repetições. As variáveis analisadas foram: toneladas de pol por hectare, toneladas de cana por hectare, fibra, pol \% corrigida, pureza, teor de sólidos solúveis, açúcares redutores e açúcar total recuperável. Após análise de variância e estimação de parâmetros genéticos, a distância generalizada de Mahalanobis foi calculada para quantificar a dissimilaridade. Foram utilizados o método hierárquico de ligações médias (UPGMA) e o método de otimização de Tocher. O coeficiente de herdabilidade média foi de alta magnitude para as variáveis TPH e TCH, indicando possibilidade de sucesso na seleção com base nesses caracteres. A metodologia aplicada permitiu a identificação de progênies de maior divergência genética proporcionando ao fitomelhoramento canavieiro da RIDESA sugestão de cruzamentos a serem realizados futuramente.
\end{abstract}

Palavras-chave - Cana-de-açúcar. Hibridação vegetal. Melhoramento genético.

\begin{abstract}
This study aimed to evaluate the genetic diversity in progenies of sugar cane by means of multivariate techniques based on eight agroindustrial traits. The work was carried out in the agricultural area of Usina Santa Teresa, Goiana (PE), during the agricultural year 2007/2008. A complete randomized block design with five replications was used. The variables analyzed were: pol tons per hectare (PTH), sugarcane tons per hectare (STH), fiber (FB), corrected pol \% (CPP), purity (PTY), content of soluble solids (BX), reducing sugar (RS) and total retrievable sugar (TRS). After analysis of variance and estimation of genetic parameters, the Mahalanobis distance was calculated for quantifying dissimilarity. We used averagelinkage method (UPGMA) and the optimization method of Tocher. The average coefficient of heritability was high for the variables PTH and STH indicating the possibility of success in selection for these characters. The methodology allowed identification of progenies with greater genetic divergence providing information for RIDESA sugarcane plant breeding on crosses to be made in the future.
\end{abstract}

Key words - Saccharum spp. Hybridization. Genetic Improvement.

\footnotetext{
* Autor para correspondência

${ }^{1}$ Recebido para publicação em 08/03/2010; aprovado em 04/02/2011

Extraído da Dissertação de Mestrado apresentada pelo primeiro autor à Universidade Federal Rural de Pernambuco

${ }^{2}$ Estação Experimental de cana-de-açúcar do Carpina, PMGCA/UFRPE/RIDESA, Rua Angela Cristina Canto Pessoa Luna s/n, Bairro Novo, Carpina-

PE, Brasil, 55.810-000, filho-dutra@ig.com.br, luizjose@hotmail.com

${ }^{3}$ Departamento de Agricultura, DAG/UFLA, Campus Universitário, Lavras-MG, Brasil, 37.200-000, luciane.vilela@ufla.br

${ }^{4}$ Departamento de Agronomia, DEPA/UFRPE, Rua Dom Manuel de Medeiros s/n, Dois Irmãos, Recife-PE, Brasil, 52.171-900, cjose@ufrpe.br,

bastosgq@hotmail.com
} 


\section{Introdução}

A variabilidade genética disponível para seleção, em cana-de-açúcar, provém de cruzamentos realizados entre genitores de interesse que já apresentam um conjunto de genes relacionados a caracteres tidos como importantes componentes de produção.

Diante de um programa de melhoramento por hibridação, a fim de desenvolver uma nova variedade, primeiramente é necessário que se tenha variabilidade genética nos progenitores envolvidos para melhor selecioná-los.

Uma alta probabilidade de obtenção de uma nova variedade se dá quando se efetuam seleção e cruzamentos entre genitores que apresentam caracteres agronômicos favoráveis (PEDROZO et al., 2009). Nesse contexto, é fundamental avaliar a divergência genética entre os genitores envolvidos, para que através dos cruzamentos realizados aumente-se a possibilidade de obtenção de indivíduos com excelente potencial heterótico (SUDRE et al., 2005).

De acordo com Shimoya et al. (2002), essa divergência genética pode ser quantificada através de métodos preditivos que levam em consideração caracteres agronômicos, fisiológicos, morfológicos e moleculares. Entre as medidas de dissimilaridade mais utilizadas nos estudados de divergência genética está à distância generalizada de Mahalanobis. Esta leva em consideração as variâncias e covariâncias residuais que existem entre as características mensuradas, possíveis de serem quantificadas, quando os genótipos são avaliados em experimentos conduzidos em delineamentos experimentais adequados (AMORIM et al., 2007).

Ao utilizar medidas de dissimilaridade, o número de estimativas obtidas é muito grande, tornando impraticável o reconhecimento de grupos homogêneos pelo simples exame visual destas estimativas. Por este motivo, o melhorista utiliza os métodos de agrupamento ou de projeções de distâncias em gráficos bidimensionais, tomando por base as coordenadas obtidas a partir da medida de dissimilaridade escolhida (CRUZ; CARNEIRO, 2006).

Os métodos de agrupamento podem ser divididos em hierárquicos e de otimização. Entre os métodos de otimização mais utilizados na área de melhoramento vegetal destaca-se o de Tocher. Neste método adota-se o critério de que a média das medidas de dissimilaridade dentro de cada grupo deve ser menor que as distâncias médias entre quaisquer grupos (CRUZ, 2005).

Nos métodos hierárquicos, os genótipos são agrupados por um processo que se repete em vários níveis até o estabelecimento de um dendrograma de alto conteúdo informativo (CRUZ, 2005).

Com este trabalho objetivou-se avaliar a divergência genética em progênies de cana-de-açúcar oriundas de autofecundação, por meio de técnicas multivariadas, com base em oito caracteres agroindustriais.

\section{Material e métodos}

$\mathrm{O}$ experimento foi conduzido na zona canavieira do Litoral Norte de Pernambuco classificado por Koffler et al. (1986), na área agrícola da Usina Santa Tereza, Engenho Terra Rica, município de Goiana, com coordenadas geográficas $07^{\circ} 33^{\prime} \mathrm{S}$ e $35^{\circ} 00^{\prime} \mathrm{W}$ e altitude de $13 \mathrm{~m}$, durante o ano agrícola 2007/2008, em Argissolo vermelho-amarelo de textura arenosa.

Foi utilizado o delineamento casualizado em blocos completos com cinco repetições. Foram avaliadas seis progênies, constituídas de 200 indivíduos cada, sendo três consideradas padrões, oriundas de multiplicação clonal das variedades comerciais RB943365, RB867515 e RB863129 e três de autofecundação dessas mesmas variedades conforme identificado (TAB. 1).

Para o controle efetivo da autofecundação utilizaramse campânulas de TNT, medindo $0,50 \mathrm{~cm}$ de raio e $1,20 \mathrm{~m}$ de comprimento, totalmente fechadas (FIG. 1).

Tabela 1 - Identificação das seis progênies de cana-de-açúcar quanto aos genitores e procedência

\begin{tabular}{lcccc}
\hline \multicolumn{1}{c}{ Progênies } & Feminino & & Genitores \\
1. RB943365 AUTO & & autofecundação & & Procedência \\
2. RB943365 & ROC3 & & RB83100 & RIDESA \\
3. RB867515 AUTO & & autofecundação & & RIDESA \\
4. RB867515 & RB72545 & & $?$ & RIDESA \\
5. RB863129 AUTO & & autofecundação & & RIDESA \\
6. RB863129 & RB763411 & & $?$ & RIDESA \\
\hline
\end{tabular}



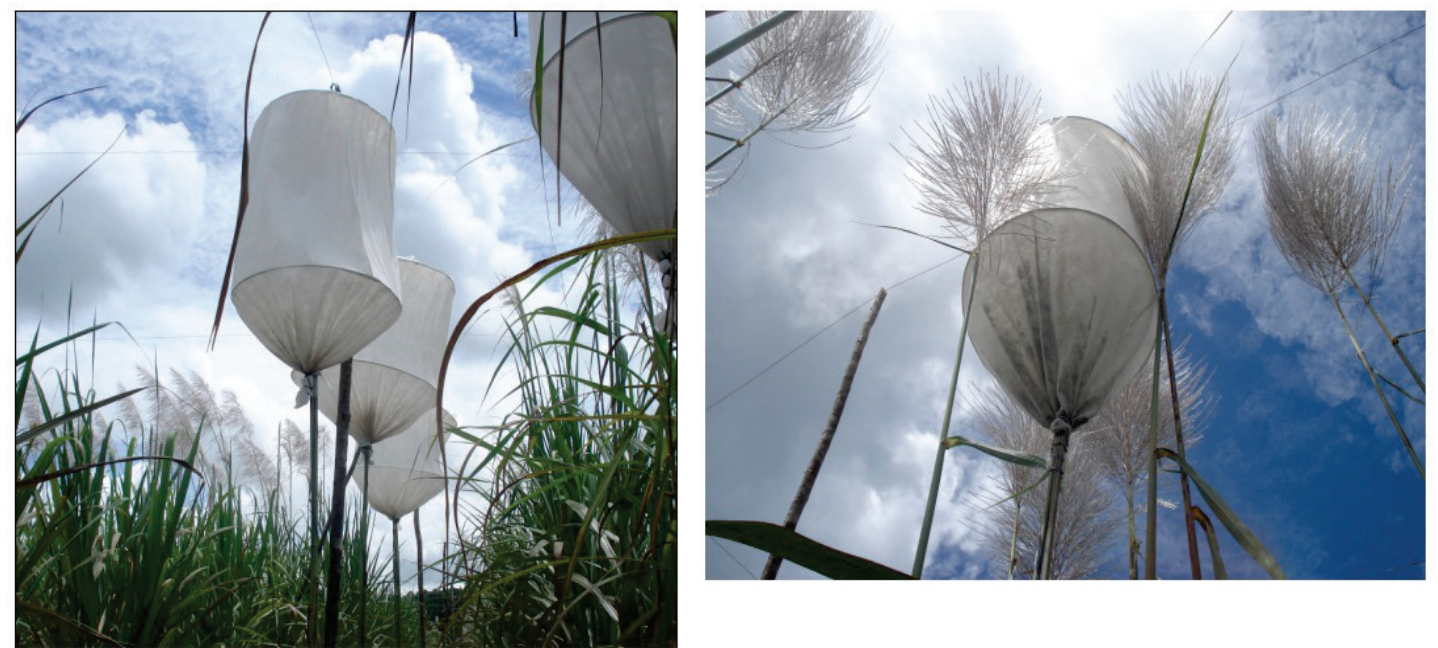

Figura 1 - Campânulas utilizadas para o controle efetivo da autofecundação das variedades comerciais RB943365, RB867515 e RB863129

Cada parcela experimental foi constituída por 5 linhas de $8 \mathrm{~m}$, espaçadas de $1,20 \mathrm{~m}$ com 8 plântulas por linha com $1 \mathrm{~m}$ entre plantas, totalizando assim 40 plântulas por parcela. As correções de $\mathrm{pH}$ do solo e adubações do campo foram realizadas conforme o sistema de produção canavieira da empresa agroindustrial.

$\mathrm{O}$ corte foi realizado na fase $\mathrm{T} 1$ cana soca. As variáveis analisadas foram: toneladas de pol por hectare (TPH), toneladas de cana por hectare (TCH), fibra (FIB), pol \% corrigida (PCC), pureza (PZA), teor de sólidos solúveis (BRIX), açúcares redutores (AR) e açúcar total recuperável (ATR).

A produtividade por área $(\mathrm{TCH})$ foi estimada efetuando-se a pesagem, em $\mathrm{kg}$, de todos os colmos da parcela, transformando-os posteriormente por meio da seguinte equação (Peso total da parcela x 10/área útil da parcela $\mathrm{em}^{2}$ ). Toneladas de pol por hectare (TPH) foi obtido por meio da expressão (TCH x PC/100). O teor de sólidos solúveis (BRIX) foi mensurado com refratômetro de campo representado por uma leitura de amostra homogênea do caldo de dez colmos, retirados ao acaso de cada parcela. Para calcular as variáveis fibra, pol \% corrigida (PCC), pureza (PZA), açúcares redutores (AR) e açúcar total recuperável (ATR), seguiu-se a metodologia proposta por Fernandes (FERNANDES, 2003).

A análise de variância foi realizada segundo a metodologia descrita por Gomes (1990), de acordo com o modelo matemático: Yij $=\mu+$ gi + bj $+\varepsilon i j$, onde, Yij: é a observação do i-ésimo genótipo no j-ésimo bloco; $\mu$ : média geral; gi: é o efeito do i-ésimo genótipo; bj: é o efeito do j-ésimo bloco; cij: é o erro aleatório associado a cada observação Yij. As médias foram agrupadas pelo teste de Scott \& Knott, ao nível de 1\% de probabilidade.

Os parâmetros genéticos foram estimados de acordo com o modelo proposto por Vencovsky e Barriga (1992), obtendo-se a variância genética e ambiental, os coeficientes de variação genética e a herdabilidade média.

Para quantificar a divergência genética entre as progênies avaliadas, utilizou-se como medida de dissimilaridade a distância generalizada de Mahalanobis, obtida por meio da expressão:

$$
\mathrm{Dii}^{2}=\delta^{\prime} \psi^{-1} \delta
$$

onde: Dii'²: é a distância de Mahalanobis entre os genótipos i e i'; $\Psi$ : matriz de variâncias e covariâncias residuais (dimensão 8); informação necessária apenas para o cálculo da distância de Mahalanobis (CRUZ;

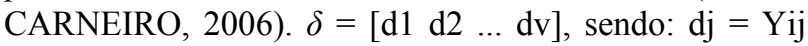
- Yi'j; $d_{v}=$ representa a diferença entre médias de dois genótipos i e i' para uma dada característica j; Yij: é a média do i-ésimo genótipo em relação à j-ésima variável.

Como técnica de agrupamento empregou-se o método de otimização de Tocher e para a construção do dendrograma utilizou-se o método hierárquico do tipo UPGMA (Unweighted Pair Group Method using Arithmetical Averages), desenvolvido por Sokal \& Michener (SOKAL; MICHENER, 1958).

As análises genético-estatísticas foram processadas com o auxílio do programa GENES (CRUZ, 2006). 


\section{Resultados e discussão}

De acordo com o teste $\mathrm{F}$ (TAB. 2), foram observadas diferenças significativas entre genótipos a $1 \%$ de probabilidade $(\mathrm{P}<0,01)$ para as variáveis toneladas de pol por hectare (TPH) e toneladas de cana por hectare $(\mathrm{TCH})$.

Foi observada variabilidade genética entre as progênies avaliadas, para esses dois caracteres, que são considerados os mais importantes componentes de produção em cana-de-açúcar (BASTOS et al., 2003). Melo et al. (2009) apresentaram resultados concordantes para essas duas variáveis.

Os valores do coeficiente de variação ( $\mathrm{CV} \%$ ) oscilaram entre baixo e médio, de acordo com a classificação proposta por Gomes (1990), variando de 4,30\% para a variável pureza (PZA) a 14,09\% para a variável toneladas de pol por hectare (TPH), confirmando assim boa precisão experimental. Bressiani (2002) apresentou semelhante faixa de valores para o coeficiente de variação em relação ao teor de sólidos solúveis (BRIX) e toneladas de cana por hectare (TCH) estimados em torno de $2,6 \%$ e $12,8 \%$ respectivamente, cuja oscilação desses valores foi classificada como baixa e média. Estudando a repetibilidade de caracteres agroindustriais em cana-de-açúcar, Santos et al. (2004), obteveram um coeficiente de variação em torno de $11,81 \%$ para a variável TPH, classificado também como médio, sendo, portanto, concordante com os resultados apresentados no presente trabalho. Para a variável açúcares redutores (AR) o coeficiente de variação foi considerado alto, estimado em torno de 55,85\%. Ramalho et al. (1993) ressaltam que essa alta variabilidade pode ser atribuída a diversos fatores, dentre os quais se podem citar: problemas de amostragem, diferenças existentes entre populações e diferenças de ambiente.

Os parâmetros genéticos estimados no presente trabalho são apresentados na Tabela 3 .

Para as variáveis toneladas de pol por hectare (TPH) e toneladas de cana por hectare $(\mathrm{TCH})$, a variância genética foi elevada e altamente superior à variância ambiental indicando que a expressão desses importantes componentes de produção, em sua maior parte, é devida aos efeitos genéticos, sugerindo assim possibilidade de sucesso para a seleção neste ambiente.

Os valores expressos pelos coeficientes de herdabilidade média foram elevados para as variáveis

Tabela 2 - Resumo da análise de variância das características avaliadas na fase T1 em cana soca, em experimento conduzido na Zona canavieira do Litoral Norte de Pernambuco, Usina Santa Tereza, Goiana - PE, ano agrícola 2007/2008

\begin{tabular}{lccccccccc}
\hline \multicolumn{1}{c}{} & \multicolumn{10}{c}{ Quadrados Médios } \\
\hline F.V. & G.L. & TPH & TCH & FIB & PCC & PZA & BRIX & AR & ATR \\
\hline Blocos & 4 & 2,30 & 50,27 & 1,65 & 1,35 & 6,69 & 1,27 & 0,04 & 102,00 \\
Tratamentos & 5 & $37,21^{* *}$ & $1.705,05^{* *}$ & $0,73^{\text {ns }}$ & $1,14^{\text {ns }}$ & $2,64^{\text {ns }}$ & $1,50^{\text {ns }}$ & $0,02^{\text {ns }}$ & $92,93^{\text {ns }}$ \\
Resíduo & 20 & 0,99 & 40,00 & 0,63 & 0,74 & 14,34 & 1,25 & 0,10 & 49,41 \\
\hline \multicolumn{1}{c}{ Média } & & 7,08 & 48,70 & 14,67 & 14,43 & 88,05 & 20,28 & 0,57 & 140,21 \\
CV (\%) & & 14,09 & 12,99 & 5,39 & 5,95 & 4,30 & 5,51 & 55,85 & 5,01 \\
\hline
\end{tabular}

** e * significativos a 1 e $5 \%$ de probabilidade, respectivamente, pelo teste $\mathrm{F}$; ${ }^{\text {ns }}$ não significativo, pelo teste $\mathrm{F}$

Tabela 3 - Estimativas de parâmetros genéticos para os caracteres avaliados na fase T1 em cana soca, em experimento conduzido na Zona canavieira do Litoral Norte de Pernambuco, Usina Santa Tereza, Goiana - PE, ano agrícola 2007/2008

\begin{tabular}{ccccccccc}
\hline Parâmetros Genéticos & TPH & TCH & FIBRA & PCC & PZA & BRIX & AR & ATR \\
\hline VG & 7,24 & 333,01 & 0,02 & 0,08 & $-2,34$ & 0,05 & $-0,02$ & 8,7 \\
VE & 0,99 & 40,01 & 0,63 & 0,74 & 14,34 & 1,25 & 0,11 & 49,41 \\
CVg (\%) & 38,02 & 37,47 & 0,96 & 1,98 & -99 & 1,11 & -99 & 2,1 \\
CVg/CVe & 2,7 & 2,89 & 0,18 & 0,33 & -99 & 0,2 & -99 & 0,42 \\
$h \mathrm{~m}^{2}(\%)$ & 97,33 & 97,65 & 13,77 & 35,63 & $-442,84$ & 16,77 & $-485,07$ & 46,83 \\
\hline
\end{tabular}

Nota: VG Variância genética; VE Variância ambiental; CVg Coeficiente de variação genética; CVe Coeficiente de variação ambiental; $h \mathrm{~m}^{2}$ Herdabilidade Média 
TPH (97,33\%) e TCH (97,65\%) mostrando predominância do componente genético sobre o ambiental. Conforme descreve Falconer (1987), a confiabilidade do valor fenotípico como indicador do valor genético neste ambiente foi altamente satisfatória e consequentemente proporciona ao fitomelhorista perspectivas favoráveis para uma seleção com base nesses caracteres, além de um indicativo de sucesso na recombinação das progênies avaliadas. Estes valores foram mais elevados do que os registrados por Melo et al. (2006) que obtiveram valores de herdabilidade média estimados em $92,4 \%$ para TPH e $94,6 \%$ para $\mathrm{TCH}$ na fase de cana soca em experimento conduzido na região da Mata Norte de Pernambuco.

Os coeficientes de variação genética para as variáveis TPH e $\mathrm{TCH}$ tiveram valores estimados em torno de $38,02 \%$ e $37,47 \%$ respectivamente, evidenciando presença de variabilidade genética e grande possibilidade de êxito na seleção. Acima de $10 \%$, os coeficientes de variação genética são considerados altos de acordo com Oliveira et al. (2008) que obtiveram resultados semelhantes. Bastos et al. (2007) obtiveram valores estimados acima de $10 \%$ para o coeficiente de variação genética e afirmaram existir considerável variabilidade genética, sendo o maior valor estimado em torno de $20 \%$ para o caráter toneladas de brix por hectare $(\mathrm{TBH})$. Com os coeficientes de variação genética estimados em valores acima de $30 \%$, no presente trabalho, reforça-se ainda mais a possibilidade de se praticar uma seleção mais efetiva entre as progênies avaliadas.

$\mathrm{O}$ agrupamento de médias pelo teste de Scott $\&$ Knott (TAB. 4) a $1 \%$ de probabilidade $(\mathrm{P}<0,01)$ possibilitou a formação de grupos, de progênies, superiores para as variáveis TPH e TCH.

Constata-se que as progênies provenientes da autofecundação foram inferiores às variedades padrões. Inicialmente poder-se-ia afirmar que a inferioridade, em relação à produtividade, seria proveniente da depressão por endogamia. No entanto, conforme exposto anteriormente na metodologia, já que as parcelas experimentais formadas pelas variedades padrões foram constituídas, nos cinco blocos do experimento, por clones das variedades comerciais, a variância observada dentro das parcelas constituídas pelas variedades padrões é puramente de natureza ambiental, pois se trata de indivíduos geneticamente idênticos.

Com a segregação complexa da cana-de-açúcar, que é uma espécie alopoliplóide, é de se esperar que as progênies originadas pela autofecundação sejam constituídas por indivíduos geneticamente superiores e inferiores. Estes últimos possivelmente contribuíram para uma diminuição na média da produtividade das progênies de autofecundação, já que para se estimar a produtividade por área (TCH), por exemplo, efetua-se a pesagem, em $\mathrm{kg}$, de todos os colmos da parcela, transformando-os posteriormente em TCH, não havendo seleção dos melhores indivíduos a serem mensurados. Mesmo assim, observa-se que a progênie oriunda da autofecundação da variedade comercial RB867515 não diferiu estatisticamente do padrão RB943365 com ralação a variável TCH.

$\mathrm{Na}$ Tabela 5, encontram-se as estimativas de dissimilaridade, com base na Distância Generalizada de Mahalanobis das progênies de cana-de-açúcar avaliadas no presente trabalho.

Observa-sequea maior divergênciagenética ocorreu entre as progênies 5 (proveniente da autofecundação) e 6 (constituída de clones da variedade comercial RB863129), cuja distância foi estimada em $\left(\mathrm{D}^{2}=64,42\right)$.

Essa divergência pode ser explicada pelo fato de as variedades comerciais, que são híbridos interespecíficos, apresentarem uma organização cromossômica complexa. Apresentando as progênies, um genoma complexo,

Tabela 4 - Agrupamento de progênies para as variáveis toneladas de pol por hectare (TPH), toneladas de cana por hectare (TCH), fibra, pureza (PZA), teor de sólidos solúveis (BRIX), açúcares redutores (AR) e açúcar total recuperável (ATR), de acordo com o teste de Scott \& Knott

\begin{tabular}{ccccccccc}
\hline $\begin{array}{c}\text { Variáveis } \\
\text { Progênies }\end{array}$ & TPH & TCH & FIBRA & PCC & PZA & BRIX & AR & ATR \\
\hline 1 & $4,99 \mathrm{~b}$ & $35,42 \mathrm{c}$ & $15,1 \mathrm{a}$ & $13,97 \mathrm{a}$ & $86,74 \mathrm{a}$ & $20,1 \mathrm{a}$ & $0,67 \mathrm{a}$ & $136,898 \mathrm{a}$ \\
$2^{*}$ & $8,11 \mathrm{a}$ & $53,3 \mathrm{~b}$ & $14,06 \mathrm{a}$ & $15,07 \mathrm{a}$ & $88,47 \mathrm{a}$ & $20,86 \mathrm{a}$ & $0,54 \mathrm{a}$ & $145,926 \mathrm{a}$ \\
3 & $6,65 \mathrm{~b}$ & $46,88 \mathrm{~b}$ & $14,96 \mathrm{a}$ & $14,17 \mathrm{a}$ & $88,9 \mathrm{a}$ & $19,84 \mathrm{a}$ & $0,5 \mathrm{a}$ & $137,17 \mathrm{a}$ \\
$4^{*}$ & $9,86 \mathrm{a}$ & $65,8 \mathrm{a}$ & $14,66 \mathrm{a}$ & $14,99 \mathrm{a}$ & $88,14 \mathrm{a}$ & $21,04 \mathrm{a}$ & $0,56 \mathrm{a}$ & $145,452 \mathrm{a}$ \\
5 & $3,04 \mathrm{c}$ & $21,01 \mathrm{~d}$ & $14,83 \mathrm{a}$ & $14,28 \mathrm{a}$ & $87,92 \mathrm{a}$ & $20,16 \mathrm{a}$ & $0,58 \mathrm{a}$ & $138,916 \mathrm{a}$ \\
$6^{*}$ & $9,83 \mathrm{a}$ & $69,79 \mathrm{a}$ & $14,42 \mathrm{a}$ & $14,08 \mathrm{a}$ & $88,13 \mathrm{a}$ & $19,7 \mathrm{a}$ & $0,56 \mathrm{a}$ & $136,91 \mathrm{a}$ \\
\hline
\end{tabular}

Médias seguidas da mesma letra pertencem ao mesmo grupo pelo teste de Scott \& knott, ao nível de 1\% de probabilidade; * Variedades Padrão 
Tabela 5 - Medidas de dissimilaridade entre seis progênies de cana-de-açúcar quantificadas pela distância generalizada de Mahalanobis $\left(\mathrm{D}^{2}\right)$

\begin{tabular}{ccccccc}
\hline \multicolumn{7}{c}{ Distância entre progênies } \\
\hline Progênies & 1 & 2 & 3 & 4 & 5 & 6 \\
1 & 0 & 13,68 & 4,46 & 27,04 & 7,45 & 31,76 \\
2 & 0 & 7,64 & 6,70 & 31,30 & 10,47 \\
3 & & 0 & 12,70 & 21,75 & 15,29 \\
4 & & & 0 & 57,11 & 3,12 \\
5 & & & & 0 & 64,42 \\
6 & & & & & 0 \\
\hline
\end{tabular}

Nota: 1. RB943365 AUTO; 2. RB943365; 3. RB867515 AUTO; 4. RB867515; 5. RB863129 AUTO; 6. RB863129

derivado de cinco espécies pertencentes ao gênero Saccharum, somando-se aos vários níveis de ploidia e múltiplos alelos segregando num mesmo loco conforme menciona Hoaral et al. (2001), este resultado é esperado.

Observa-se ainda divergência genética satisfatória entre as progênies 4 e 5 , com um valor estimado em torno de $\left(D^{2}=57,11\right)$. A maior similaridade genética $\left(D^{2}=3,12\right)$ foi observada entre as progênies 4 e 6 .

O método de otimização de Tocher (TAB. 6), com base na distância generalizada de Mahalanobis, agrupou as seis progênies avaliadas em quatro grupos distintos.

Tabela 6 - Grupos de dissimilaridade formados pelo método de otimização de Tocher, baseado na distância generalizada de Mahalanobis

\begin{tabular}{|c|c|c|}
\hline Grupos & Genótipos & $\%$ \\
\hline I & $4^{*} 6^{*}$ & 33,3 \\
\hline II & 13 & 33,3 \\
\hline III & $2^{*}$ & 16,7 \\
\hline IV & 5 & 16,7 \\
\hline
\end{tabular}

* Variedades Padrões

O grupo I foi formado por duas progênies constituídas de duas variedades comerciais RB867515 e RB863129; o grupo II por duas progênies oriundas de autofecundação das variedades RB943365 e RB867515. Isoladamente nos grupos III e IV, enquadraram-se, respectivamente, a progênie constituída por clones da variedade comercial RB943365 e a progênie oriunda da autofecundação da variedade RB863129.

Neste tipo de análise, é comum que os primeiros grupos tenham um maior número de indivíduos que os últimos. Elias et al. (2007), avaliando a variabilidade genética em germoplasma tradicional de feijão preto, afirmaram que o método de otimização de Tocher tem como princípio manter a homogeneidade dentro dos grupos e a heterogeneidade entre os grupos, assim sendo, o maior número de indivíduos em um determinado grupo indica que eles apresentam maior similaridade genética e os indivíduos enquadrados no último grupo apresentam maior divergência em relação àqueles que estão no primeiro grupo.

Silva (2005), utilizando técnicas multivariadas para avaliar a divergência genética em 129 clones de cana-de-açúcar em experimento conduzido em Paranavaí, observou, pelo método de Tocher, a formação de 7 grupos onde o primeiro foi constituído por 108 clones representando $83,72 \%$ dos que foram estudados. Do grupo 2 ao 7 foram enquadrados $9 ; 3 ; 3 ; 4 ; 1$ e 1 clones, representando respectivamente $6,97 \% ; 2,32 \% ; 2,32 \%$; $3,10 \% ; 0,77 \%$ e $0,77 \%$ dos que foram avaliados.

O dendrograma de similaridade obtido pelo método UPGMA (FIG. 2) possibilitou a formação de dois grandes grupos.

O grupo I é formado pelas progênies $(4 ; 6$ e 2$)$ e o grupo II é formado pelas progênies ( $1 ; 3$ e 5$)$. Observa-se ainda que o grupo I pode ser dividido em dois subgrupos. $\mathrm{O}$ subgrupo IA formado pelas progênies (4 e 6) e o subgrupo IB formado pela progênie (2). O grupo II também pode ser dividido em dois subgrupos. O subgrupo IIA formado pelas progênies (1 e 3) e o subgrupo IIB formado pela progênie (5). Concluí-se assim que o método hierárquico UPGMA agrupou de maneira similar ao método de otimização de Tocher as progênies avaliadas, sendo os subgrupos IB e IIB correspondentes aos grupos 3 e 4 do agrupamento pelo método de Tocher.

Estes resultados proporcionam ao programa de fitomelhoramento canavieiro da RIDESA informações 


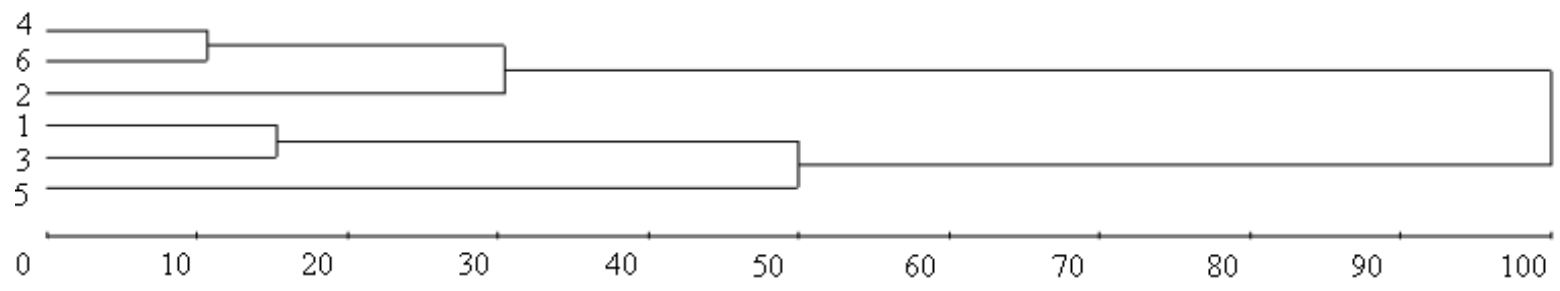

Figura 2 - Dendrograma representativo do padrão de dissimilaridade, estabelecido pelo método hierárquico das ligações médias (UPGMA), baseado na distância generalizada de Mahalanobis para as seis progênies de cana-de-açúcar

consistentes sobre os cruzamentos a serem realizados, com perspectivas favoráveis de obtenção de indivíduos desejáveis e com um excelente potencial heterótico.

\section{Conclusões}

1. Os coeficientes de herdabilidade média de alta magnitude para as variáveis TPH e TCH indicam alta probabilidade de êxito na seleção com base nesses caracteres da cana-de-açúcar;

2. As técnicas multivariadas mostraram-se eficientes na identificação das progênies mais divergentes no material genético considerado;

3. Cruzamentos da progênie 5 (RB863129AUTO) com as progênies 4 (RB867515) e 6 (RB863129) são promissoras para a geração de novas combinações de alelos favoráveis para a obtenção de indivíduos geneticamente superiores com excelente potencial heterótico.

\section{Agradecimentos}

À Universidade Federal Rural de Pernambuco (UFRPE), Estação Experimental de Cana-de-açúcar do Carpina (EECAC), Rede Interuniversitária de Desenvolvimento do Setor Sucroalcooleiro (RIDESA) e à Usina Santa Tereza por todo o apoio concedido e viabilização da pesquisa e ao Conselho Nacional de Desenvolvimento Científico e Tecnológico (CNPq) pela concessão da bolsa de estudos.

\section{Referências}

AMORIM, E. P. et al. Divergência genética em genótipos de girassol. Ciência e Agrotecnologia, v. 31, n. 06, p. 1637 1644, 2007.
BASTOS, I. T. et al. Análise dialélica em clones de cana-deaçúcar. Bragantia, v. 62, n. 02, p. 199-206, 2003.

BASTOS, I. T. et al. Avaliação da interação genótipo x ambiente em cana-de-açúcar via modelos mistos. Pesquisa Agropecuária Tropical, v. 37, n. 04, p.195-203. 2007.

BRESSIANI, J. A.; VENCOVSKY, R.; BURNQUIST, W. L. Interação entre famílias de cana-de-açúcar e locais: efeito na resposta esperada com a seleção. Bragantia, v. 61, n. 01, p. 1-10. 2002.

CRUZ, C. D. Princípios de genética quantitativa. Viçosa: UFV, 2005. 394 p.

CRUZ, C. D. Programa GENES: aplicativo computacional em genética e estatística. Viçosa: UFV, 2006. 442 p.

CRUZ, C. D.; CARNEIRO, P. C. S. Modelos biométricos aplicados ao melhoramento genético. 2. ed. Viçosa: UFV, 2006. 585 p.

ELIAS, H. T. et al. Variabilidade genética em germoplasma tradicional de feijão preto em Santa Catarina. Pesquisa Agropecuária Brasileira, v. 42, n. 10, p. 1443-1449, 2007.

FALCONER, D. S. Introdução a genética quantitativa. Viçosa: UFV, 1987. 279 p.

FERNANDES, A. C. Cálculos na agroindustria da cana-deaçúcar. 2. ed. Piracicaba: EME, 2003. 240 p.

GOMES, F. P. Curso de estatística experimental. 13. ed. Piracicaba: USP, 1990. 467 p.

HOARAU, J.Y. et al. Genetic dissection of a modern sugarcane cultivar (Saccharum spp.). I. Genome mapping with AFLP markers. Theoretical and Applied Genetics, v. 103, n. 01, p. 84-97, 2001.

KOFFLER, N. F. et al. Caracterização edafo-climática das regiões canavieiras do Brasil: PERNAMBUCO. Piracicaba: IAA/PLANALSUCAR, $1986.78 \mathrm{p}$.

MELO, L. J. O. T. et al. Interação genótipo x ciclos de colheita de cana-de-açúcar da Zona da mata Norte de Pernambuco. Bragantia, v. 65, n. 02, p. 197-205, 2006.

MELO, L. J. O. T. et.al. Desempenho agroindustrial de cultivares de cana-de-açúcar na zona da mata litoral sul de Pernambuco. Ciência e Agrotecnologia, v. 33, n. 03, p. 684-691, 2009. 
OLIVEIRA, R. A. et al. Seleção de famílias de cana-deaçúcar via modelos mistos. Scientia Agrária, v. 09, n. 03, p.269-274, 2008.

PEDROZO, C. A. et al. Eficiência de Índices de seleção utilizando a metodologia REML/BLUP no melhoramento da cana-de-açúcar. Scientia Agrária, v. 10, n. 01, p. 031-036, 2009.

RAMALHO, M. A. P.; SANTOS, J. B.; ZIMMERMANN, M. J. O. Genética quantitativa em plantas autógamas: aplicações ao melhoramento do feijoeiro. Goiânia: UFG, 1993. $271 \mathrm{p}$.

SANTOS, M. S. M. Repetibilidade de características agroindustriais em cana-de-açúcar. Pesquisa Agropecuária Brasileira, v. 39, n. 04, p. 301-306, 2004.
SHIMOYA, A. et al. Divergência genética entre acessos de um banco de germoplasma de capim-elefante. Pesquisa Agropecuária Brasileira, v. 37, n. 07, p. 971-980, 2002.

SILVA, C. M. et al. Genetic diversity among sugarcane clones (Saccharum spp.). Acta Scientiarum Agronomy, v. 27, n. 02, p. 315-319, 2005.

SOKAL, R. R.; MICHENER, D. A statistical method for evaluation systematic relationships. University of Kansas Scientific Bulletin, v. 38, n. 22, p. 1409-1438, 1958.

SUDRE, C. P. et al. Divergência genética entre acessos de pimenta e pimentão utilizando técnicas multivariadas. Horticultura Brasileira, v. 23, n. 01, p. 22-27, 2005.

VENCOVSKY, R.; BARRIGA, P. Genética biométrica no fitomelhoramento. Ribeirão Preto: SBG, 1992. 496 p. 